\title{
Diets with High or Low Protein Content and Glycemic Index for Weight-Loss Maintenance
}

\author{
Thomas Meinert Larsen, Ph.D., Stine-Mathilde Dalskov, M.Sc., \\ Marleen van Baak, Ph.D., Susan A. Jebb, Ph.D., Angeliki Papadaki, Ph.D., \\ Andreas F.H. Pfeiffer, M.D., J. Alfredo Martinez, Ph.D., \\ Teodora Handjieva-Darlenska, M.D., Ph.D., Marie Kunešová, M.D., Ph.D., \\ Mats Pihlsgård, Ph.D., Steen Stender, M.D., Ph.D., Claus Holst, Ph.D., \\ Wim H.M. Saris, M.D., Ph.D., and Arne Astrup, M.D., Dr.Med.Sc., \\ for the Diet, Obesity, and Genes (Diogenes) Project
}

\section{ABSTRACT}

From the Department of Human Nutrition, Faculty of Life Sciences (T.M.L., S.-M.D., A.A.), and the Department of Clinical Biochemistry, Gentofte Hospital (S.S.), University of Copenhagen; and the Institute of Preventive Medicine, Copenhagen University Hospital (M.P., C.H.) - all in Copenhagen; the NUTRIM (Nutrition and Toxicology Research Institute Maastricht) School for Nutrition, Toxicology and Metabolism, Department of Human Biology, Maastricht University Medical Centre, Maastricht, the Netherlands (M.B., W.H.M.S.); the Medical Research Council Human Nutrition Research, Elsie Widdowson Laboratory, Cambridge, United Kingdom (S.A.J.); the Department of Social Medicine, Preventive Medicine, and Nutrition Clinic, University of Crete, Heraklion, Crete, Greece (A.P.); the Department of Clinical Nutrition, German Institute of Human Nutrition Potsdam-Rehbrücke, Nuthetal, Germany (A.F.H.P.); the Department of Endocrinology, Diabetes, and Nutrition, Charité Universitätsmedizin Berlin, Berlin (A.F.H.P.); the Department of Physiology and Nutrition, University of Navarra, Pamplona, Spain (J.A.M.); the Department of Pharmacology and Toxicology, Medical Faculty, National Transport Hospital, Sofia, Bulgaria (T.H.-D.); and the Obesity Management Center, Institute of Endocrinology, Prague, Czech Republic (M.K.). Address reprint requests to Dr. Larsen at the Department of Human Nutrition, Faculty of Life Sciences, University of Copenhagen, Rolighedsvej 30, 1958 Frederiksberg, Copenhagen, Denmark, orattml@life.ku.dk.

N Engl J Med 2010;363:2102-13.

Copyright (c) 2010 Massachusetts Medical Society.

\section{BACKGROUND}

Studies of weight-control diets that are high in protein or low in glycemic index have reached varied conclusions, probably owing to the fact that the studies had insufficient power.

\section{METHODS}

We enrolled overweight adults from eight European countries who had lost at least $8 \%$ of their initial body weight with a 3.3-MJ (800-kcal) low-calorie diet. Participants were randomly assigned, in a two-by-two factorial design, to one of five ad libitum diets to prevent weight regain over a 26-week period: a low-protein and low-glycemicindex diet, a low-protein and high-glycemic-index diet, a high-protein and lowglycemic-index diet, a high-protein and high-glycemic-index diet, or a control diet.

RESULTS

A total of 1209 adults were screened (mean age, 41 years; body-mass index [the weight in kilograms divided by the square of the height in meters], 34), of whom 938 entered the low-calorie-diet phase of the study. A total of 773 participants who completed that phase were randomly assigned to one of the five maintenance diets; 548 completed the intervention (71\%). Fewer participants in the high-protein and the lowglycemic-index groups than in the low-protein-high-glycemic-index group dropped out of the study (26.4\% and $25.6 \%$, respectively, vs. $37.4 \% ; \mathrm{P}=0.02$ and $\mathrm{P}=0.01$ for the respective comparisons). The mean initial weight loss with the low-calorie diet was $11.0 \mathrm{~kg}$. In the analysis of participants who completed the study, only the lowprotein-high-glycemic-index diet was associated with subsequent significant weight regain (1.67 kg; 95\% confidence interval [CI], 0.48 to 2.87). In an intention-to-treat analysis, the weight regain was $0.93 \mathrm{~kg}$ less $(95 \% \mathrm{CI}, 0.31$ to 1.55$)$ in the groups assigned to a high-protein diet than in those assigned to a low-protein $\operatorname{diet}(\mathrm{P}=0.003)$ and $0.95 \mathrm{~kg}$ less $(95 \% \mathrm{CI}, 0.33$ to 1.57$)$ in the groups assigned to a low-glycemic-index diet than in those assigned to a high-glycemic-index diet $(\mathrm{P}=0.003)$. The analysis involving participants who completed the intervention produced similar results. The groups did not differ significantly with respect to diet-related adverse events.

\section{CONCLUSIONS}

In this large European study, a modest increase in protein content and a modest reduction in the glycemic index led to an improvement in study completion and maintenance of weight loss. (Funded by the European Commission; ClinicalTrials.gov number, NCT00390637.) 
T HE IMPORTANCE OF THE COMPOSITION of a diet for the prevention and management of obesity is debated. Ad libitum consumption of low-fat diets results in short-term weight loss, ${ }^{1}$ and low-carbohydrate, high-protein, and high-fat diets (e.g., the Atkins diet) may result in substantial weight loss as compared with that achieved with other types of diets. ${ }^{2}$ However, the weight loss is generally not sustained beyond 1 year. $^{3}$ Greater weight loss with low-carbohydrate diets may be ascribed to the satiating effects of high protein content, ${ }^{4}$ and there is increasing interest in the efficacy of diets that have a high protein content with a moderate carbohydrate and fat content. ${ }^{5-7}$

A diet with a low glycemic index may have beneficial effects on body weight and body composition $^{8,9}$ and on certain risk factors in overweight persons, ${ }^{9,10}$ but the effectiveness of ad libitum consumption of low-glycemic-index diets for weight control is controversial. ${ }^{9}$ The Diet, Obesity, and Genes (Diogenes) study is a pan-European, multicenter, randomized, dietary-intervention study designed to assess the efficacy of moderatefat diets that vary in protein content and glycemic index for preventing weight regain and obesityrelated risk factors after weight loss. We report here the results of the 26-week weight-maintenance intervention phase of the study.

\section{METHODS}

\section{STUDY PROTOCOL}

The study design, methods, and procedures have been described in detail previously. ${ }^{11}$ The study was conducted in eight European countries: Denmark, the Netherlands, the United Kingdom, Greece (Crete), Germany, Spain, Bulgaria, and the Czech Republic. The overall study leaders, together with the principal investigator at each study center, designed the study. The principal investigator at each study center collected the local data, which were entered into a data-registration system (EpiData) ${ }^{12}$ and transferred to a central data hub. The European Commission Food Quality and Safety Priority of the Sixth Framework Programme (the main sponsor of the study) had no role in the design of the study or in the analysis or interpretation of the data. The protocol, including the statistical analysis plan, is available with the full text of this article at NEJM.org. The authors attest that the study was performed in accordance with the protocol and the statistical analysis plan.

\section{STUDY PARTICIPANTS}

Families that included at least one healthy child between 5 and 17 years of age and at least one parent between 18 and 65 years of age who was overweight or obese (body-mass index [the weight in kilograms divided by the square of the height in meters] of at least 27 and less than 45) were recruited for the study. Overweight or obese parents who had achieved the targeted weight loss ( $\geq 8 \%$ of their baseline weight) during the 8-week low-calorie-diet period were randomly assigned with their families to one of five maintenance diets for 26 weeks; randomization was performed with the use of a simple block randomization procedure with stratification. ${ }^{11}$ Of 1209 adults screened, 938 started the low-calorie-diet period. After completion of this phase of the study, 773 participants entered the weight-maintenance phase (Fig. 1). Results for nonobese adults and children in the study families are not reported here.

\section{WEIGHT-LOSS PHASE}

During the 8-week weight-loss phase, participants received a low-calorie diet that provided 3.3 MJ (800 kcal) per day with the use of Modifast products (Nutrition et Santé). Participants could also eat up to $400 \mathrm{~g}$ of vegetables, providing a total, including the low-calorie diet, of 3.3 to $4.2 \mathrm{MJ}$ (800 to $1000 \mathrm{kcal}$ ) per day.

\section{WEIGHT-MAINTENANCE PHASE}

In the randomized maintenance phase, which was initiated immediately after participants completed the weight-loss phase, participants were assigned to one of five diets, in a two-by-two factorial design: a diet that was low in protein $(13 \%$ of total energy consumed) with a low glycemic index, a diet that was low in protein with a high glycemic index, a diet that was high in protein $(25 \%$ of total energy consumed) with a low glycemic index, a highprotein and high-glycemic-index diet, or a control diet. The control diet, which followed dietary guidelines in each participating country, had a moderate protein content and did not include instructions to participants with respect to the glycemic index.

Study participants were instructed to maintain their weight loss during this phase, although fur- 


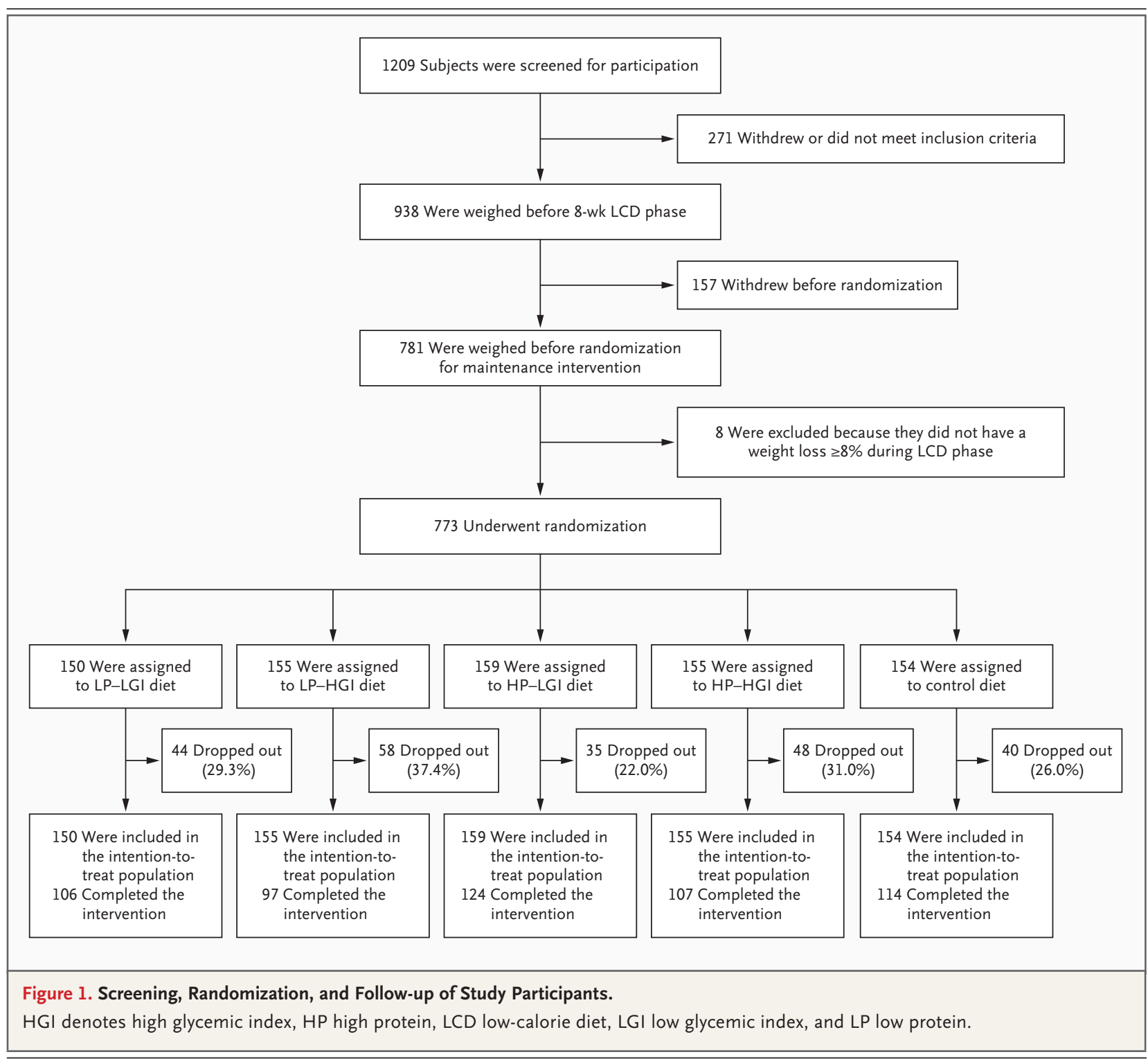

ther weight reduction was allowed. All five diets were designed to have a moderate fat content (25 to $30 \%$ of total energy consumed) with no restrictions on energy intake (i.e., ad libitum diets), in order to test the ability of the diets to regulate appetite and body weight. We targeted a difference of 15 glycemic-index units between the high-glycemic-index diets and the low-glycemicindex diets and a difference of $12 \%$ of total energy consumed from protein between the highprotein diets and the low-protein diets. Visits for dietary counseling took place every other week during the first 6 weeks and monthly thereafter. The families were provided with recipes, cooking and behavioral advice, and a point-based teaching system to achieve the targeted macronutrient compositions. ${ }^{13}$

In Maastricht and Copenhagen ("shop centers"), the families received dietary instruction plus free foods from the laboratory shop for 26 weeks so that we could assess the effect that the provision of food would have on adherence. In the other six centers ("instruction centers"), the families were provided with dietary instruction only. ${ }^{14,15}$ Local sponsors made financial contributions to the shop centers, and food manufacturers provided a number of foods free of charge. The local sponsors and food manufac- 
turers had no influence on the selection of foods found in the two shops, nor were they involved in designing the study or in analyzing and interpreting data.

\section{MONITORING FOOD INTAKE}

The study participants weighed their food and completed food diaries for 3 consecutive days at the time of screening ( 9 to 11 weeks before randomized assignment to the maintenance intervention), 4 weeks after randomization, and at the end of the 26-week intervention. The calculation of nutrient intake was performed with the use of local food databases, as described previously. ${ }^{11}$ Coding of food according to the glycemic index was performed separately from coding according to nutrient intake. Values for the glycemic index were based on glucose as a reference, as described previously. ${ }^{16}$ Blood samples were obtained before the intervention and at the end of the intervention, and urine samples before the intervention, at weeks 4 and 14, and at the end of the intervention, to assess adherence to the diet. ${ }^{11} \mathrm{~A}$ description of the method used for performing urinary analyses is provided in the Supplementary Appendix, available at NEJM.org.

\section{STATISTICAL ANALYSIS}

Estimates of the sample size were calculated with the assumption that after the 26-week intervention, the smallest difference in weight change (estimated to be $1.0 \mathrm{~kg}$ ) that would be detected among the diet groups would be found between the groups assigned to low-glycemic-index diets and the groups assigned to high-glycemic-index diets. We estimated that a sample of 918 adults would be needed to detect a significant difference between the high-glycemic-index and low-glycemic-index groups, assuming a dropout rate of $20 \% .{ }^{11}$

Dietary intakes were calculated for participants who completed food diaries, and changes from screening to the end of the intervention phase were calculated only for study participants who completed food diaries at both those times (393 participants). Mean intakes of energy and macronutrients, the glycemic index, and the glycemic load were compared with the use of one-way analysis of variance. When an overall significant difference in the effect of dietary group was found, pairwise comparisons of the groups were performed with Sidak's adjustment for multiple comparisons.

The intention-to-treat analysis included data from all participants who underwent randomization. To account for bias resulting from different rates of dropout among the groups, we used a mixed model to evaluate the weight changes (assessed at eight time points during the 26-week intervention). This intention-to-treat model provides unbiased results under the assumption that missing data were missing at random. ${ }^{17}$ The model considered all available weight recordings during the intervention for all participants who underwent randomization and assumed that the weight changes in participants who dropped out of the study followed the same course. The analyses were adjusted for the body-mass index at the time of randomization and the change in body weight from the beginning of the low-calorie-diet phase to the time of randomization as covariates and diet group, sex, and type of center (shop or instruction) as factors. The interactions between diet and sex and between diet and type of center were included in the model. It was assumed that the correlation between weight regain at two visits decreased with the number of weeks between the visits and that the decrease per week was constant.

The completion analysis, which included all participants for whom data were available from both the time of randomization and the end of the trial intervention, was performed with the use of analysis of covariance. In addition, a linear regression analysis was performed to test the main effects of protein and glycemic index separately. In both analyses, we adjusted for the same covariates as in the intention-to-treat analysis described above, as well as for the length of time between randomization and the end of the intervention.

The influence of center, type of center (shop or intervention), sex, age at screening, body-mass index at the time of randomization, body weight lost during the low-calorie-diet phase, family type (single-parent family, two-parent family with one parent as participant, or two-parent family with both parents as participants), and diet on the dropout rate during the maintenance phase was analyzed with the use of a logistic model.

Results are presented as means $\pm \mathrm{SD}$, and estimates of effects as means and $95 \%$ confidence intervals. Two-tailed P values of less than 0.05 were considered to indicate statistical significance. The analyses were performed with the use of SAS software, version 9.1. 


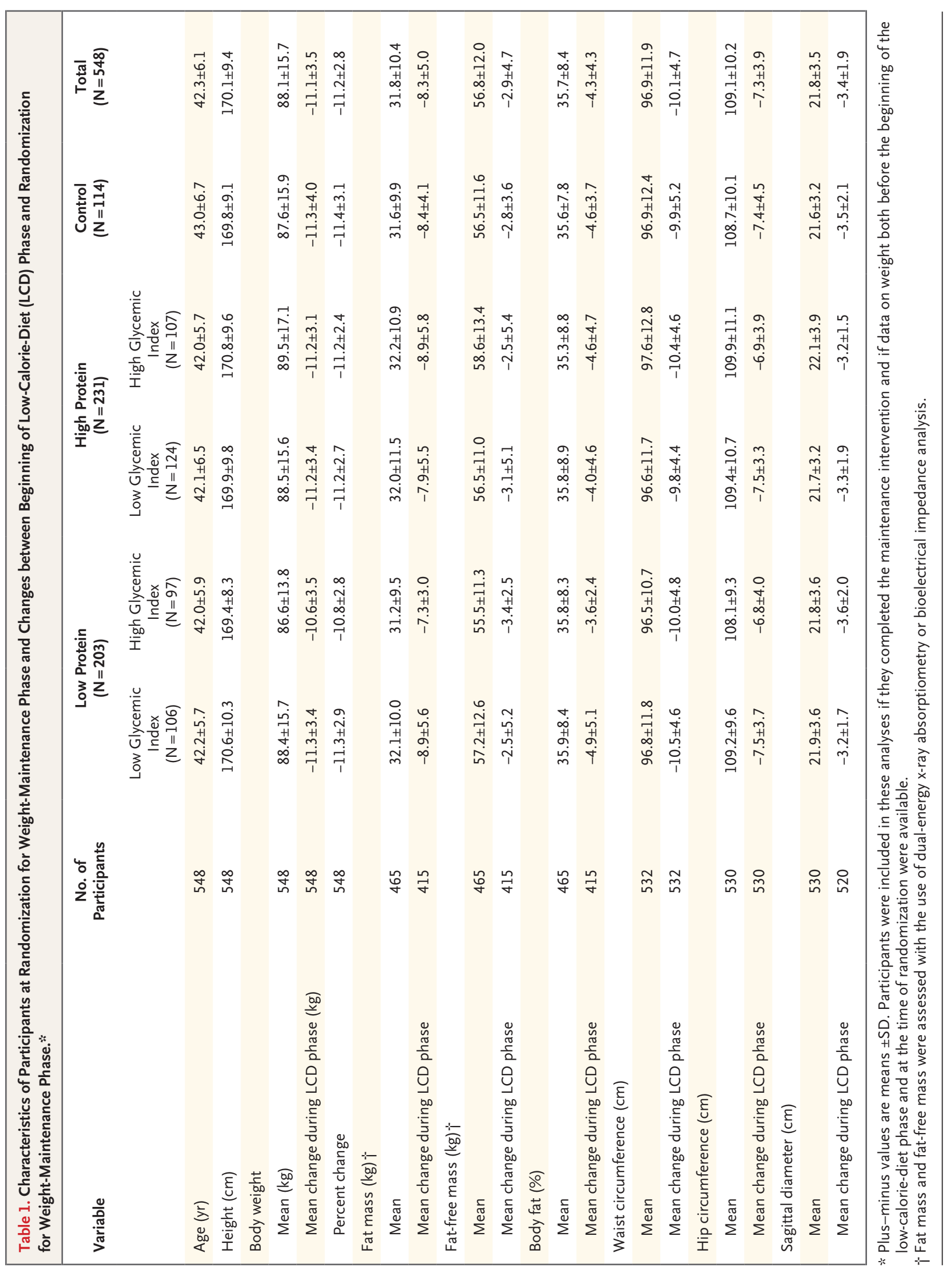




\section{RESULTS}

\section{STUDY PARTICIPANTS}

The participants in the five diet groups were well matched with respect to characteristics at baseline (i.e., at the beginning of the low-calorie-diet phase) and at the time of randomization, with no significant between-group differences in changes during the low-calorie-diet phase (Table 1). During the dietary-intervention period, 225 of the 773 participants who had undergone randomization (29\%) dropped out of the study (Fig. 1). The dropout rate was lower in the groups that were assigned to highprotein diets and the groups that were assigned to low-glycemic-index diets than in the group that was assigned to the diet that was low in protein and had a high glycemic index $(26.4 \%$ and $25.6 \%$, respectively, vs. $37.4 \% ; \mathrm{P}=0.02$ and $\mathrm{P}=0.01$ for the two comparisons, respectively). The low-glycemicindex diets were associated with a lower risk of dropout than were the high-glycemic-index diets (odds ratio, 0.64; 95\% confidence interval [CI], 0.44 to $0.92 ; \mathrm{P}=0.02$ ), and there was a trend toward a lower risk of drop-out with the high-protein diets than with the low-protein diets (odds ratio, 0.69; $95 \% \mathrm{CI}, 0.48$ to $1.00 ; \mathrm{P}=0.05$ ).

\section{DIETARY INTAKE}

Dietary intakes for all groups are shown in Table 2. The proportion of total energy consumed from protein was 5.4 percentage points higher, and the proportion of total energy consumed from carbohydrates was 7.1 percentage points lower, in the high-protein groups than in the low-protein groups ( $\mathrm{P}<0.001$ for both comparisons). The mean glycemic index in the low-glycemic-index groups was only 5 units lower than that in the high-glycemicindex groups $(\mathrm{P}<0.001)$. There was a 71\% (20.6-gper-day) greater reduction in the glycemic load in the high-protein groups than in the low-protein groups $(\mathrm{P}=0.002)$. There were no significant differences among the groups in the recordings of subjective appetite sensations (data not shown).

\section{MARKERS OF ADHERENCE TO DIET}

The urinary excretion of nitrogen during the maintenance period was greater by 2.09 g per 24 hours in the high-protein groups than in the low-protein groups $(\mathrm{P}<0.001)$ (Fig. $2 \mathrm{~A})$, and the difference remained significant when the analysis included only participants from whom more than $500 \mathrm{ml}$ of urine had been collected and more than $80 \%$ but less than $120 \% \mathrm{p}$-aminobenzoic acid had been recovered. In addition, the plasma urea concentration was higher in the high-protein groups than in the low-protein groups (between-group difference, $0.27 \mathrm{mmol}$ per liter; $\mathrm{P}=0.01$ ).

\section{BODY WEIGHT}

\section{Intention-to-Treat Analysis}

The intention-to-treat analysis, performed with the use of a mixed linear model, included all 773 participants who underwent randomization, of whom 705 attended at least one visit after randomization. The weight increase during the maintenance period was $0.93 \mathrm{~kg}$ ( $95 \% \mathrm{CI}, 0.31$ to 1.55$)$ higher in the low-protein groups than in the high-protein groups $(\mathrm{P}=0.003)$ and $0.95 \mathrm{~kg}(95 \% \mathrm{CI}, 0.33$ to 1.57) higher in the high-glycemic-index groups than in the low-glycemic-index groups $(\mathrm{P}=0.003)$ (Fig. 2B). There was no significant interaction between the high-protein diets and the low-glycemicindex diets. We performed a sensitivity analysis, assuming a 1-kg weight gain per month in participants who had dropped out of the study. This analysis produced similar results - a weight increase that was $1.01 \mathrm{~kg}$ (95\% CI, 0.24 to 1.78 ) higher in the low-protein groups than in the highprotein groups $(\mathrm{P}=0.01)$ and $0.99 \mathrm{~kg}(95 \% \mathrm{CI}$, 0.22 to 1.76 ) higher in the high-glycemic-index groups than in the low-glycemic-index groups $(\mathrm{P}=0.01)$. The high-protein groups were more likely to achieve an additional weight loss of more than $5 \%$ of their body weight at randomization than were the low-protein groups (odds ratio, 1.92; 95\% CI, 1.06 to 3.45; $\mathrm{P}=0.03$ ), and the lowglycemic-index groups were more likely to achieve an additional weight loss of more than $5 \%$ than were the high-glycemic-index groups (odds ratio, 2.54; 95\% CI, 1.38 to 4.66; $\mathrm{P}=0.003$ ) (Table 3).

\section{Completion Analysis}

In the analysis of 548 participants who completed the intervention, the mean $( \pm S D)$ weight regain was $0.56 \pm 5.44 \mathrm{~kg}$. Only the participants assigned to the diet that was low in protein with a high glycemic index had significant weight regain $(1.67 \mathrm{~kg}$; 95\% CI, 0.48 to 2.87) (Table 2). The changes in body weight differed among the diet groups ( $\mathrm{P}=0.01$ by analysis of covariance). The isolated effect size of the high-protein diets as compared with the low-protein diets was $1.44 \mathrm{~kg}(95 \% \mathrm{CI}$, 0.50 to 2.33; $\mathrm{P}=0.02$ ). The effect size of the lowglycemic-index diets as compared with the high- 


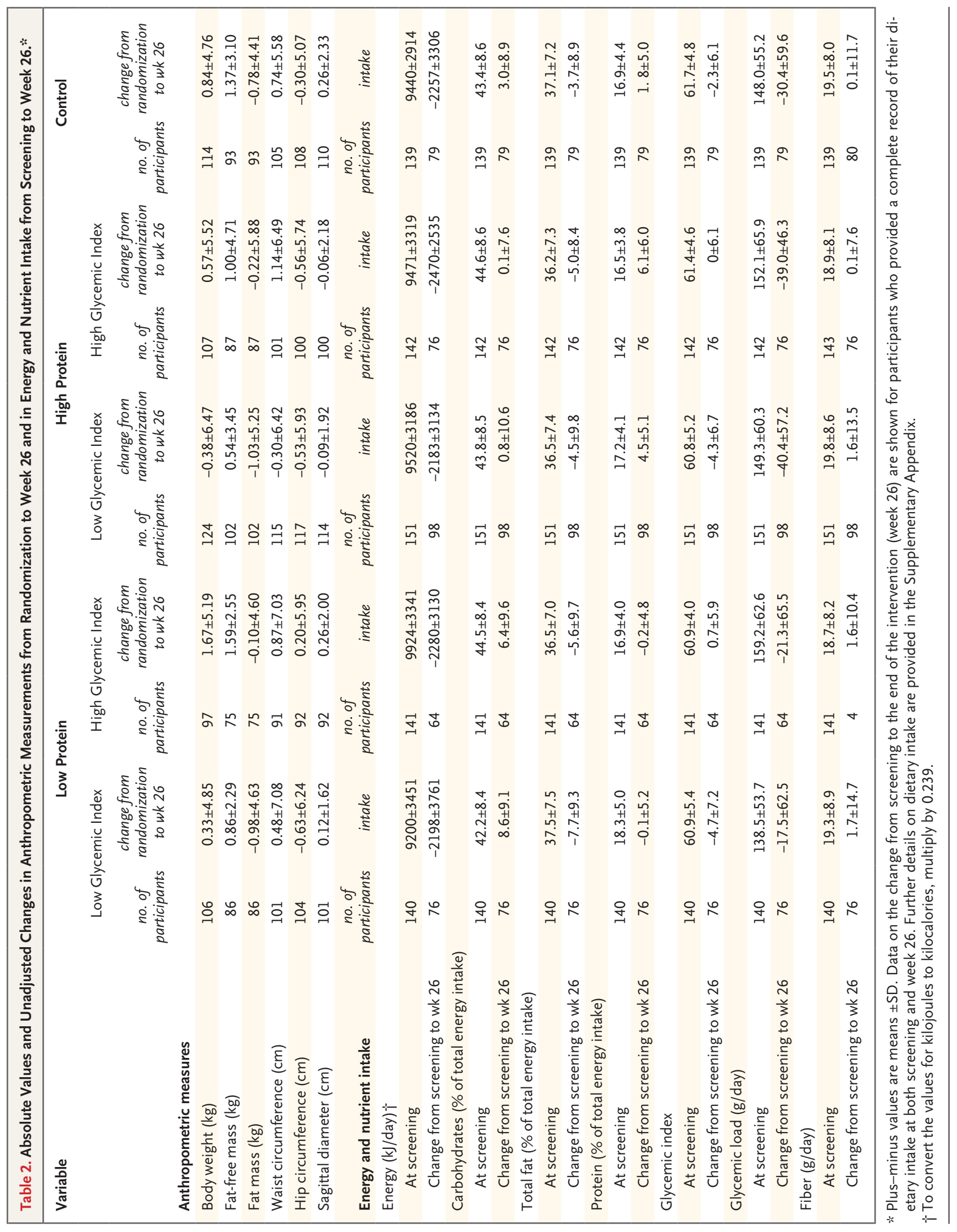


Figure 2. Total 24-Hour Urinary Nitrogen Excretion and Changes in Body Weight.

Panel A shows 24-hour urinary nitrogen excretion, as a marker of dietary protein intake, from the time before the low-calorie diet (LCD) was initiated through the end of the weight-maintenance intervention. Panel B shows the change in weight for each of the dietary groups during the weight-maintenance intervention, adjusted for body-mass index at randomization, weight loss during the low-calorie-diet phase, sex, family type (single-parent family, two-parent family with one parent as participant, or two-parent family with both parents as participants), center, and age at screening, on the basis of an intention-to-treat mixed-model analysis. The changes in body weight from randomization to week 26 among participants who completed the intervention are also shown (boxes). All participants who underwent randomization and for whom data on weight at the time of randomization were available were included. $\mathrm{HGI}$ denotes high glycemic index, HP high protein, LGI low glycemic index, and LP low protein.

glycemic-index diets was $1.09 \mathrm{~kg}$ (95\% CI, 0.18 to $2.00 ; \mathrm{P}=0.02)$. The effects of protein and glycemic index on body-weight changes in the shop centers were consistent with the results in the instruction centers, but analyzing the centers separately reduced the statistical power. In the shop centers, the high-protein groups gained $2.7 \mathrm{~kg}$ less body weight than did the low-protein groups $(\mathrm{P}<0.001)$, whereas the difference was $0.54 \mathrm{~kg}$ in the instruction centers $(\mathrm{P}=0.13)$. In the shop centers, the lowglycemic-index groups gained $0.48 \mathrm{~kg}$ less than did the high-glycemic-index groups $(\mathrm{P}=0.48)$, whereas the difference was $1.03 \mathrm{~kg}$ in the instruction centers $(\mathrm{P}=0.004)$.

\section{ADVERSE EVENTS}

Four serious adverse events were reported during the weight-maintenance period. One person assigned to the low-protein-low-glycemic-index diet presented with lower abdominal pain but recovered without the need for hospitalization. Another person assigned to the low-protein-low-glycemicindex diet who presented with abdominal pain and two persons assigned to the low-protein-highglycemic-index diet who presented with upper abdominal pain were hospitalized; each had his or her gall bladder removed and recovered without further consequences. The number of adverse events was lower in the group assigned to the diet that was low in protein with a high glycemic index than in any of the other groups, but the pattern

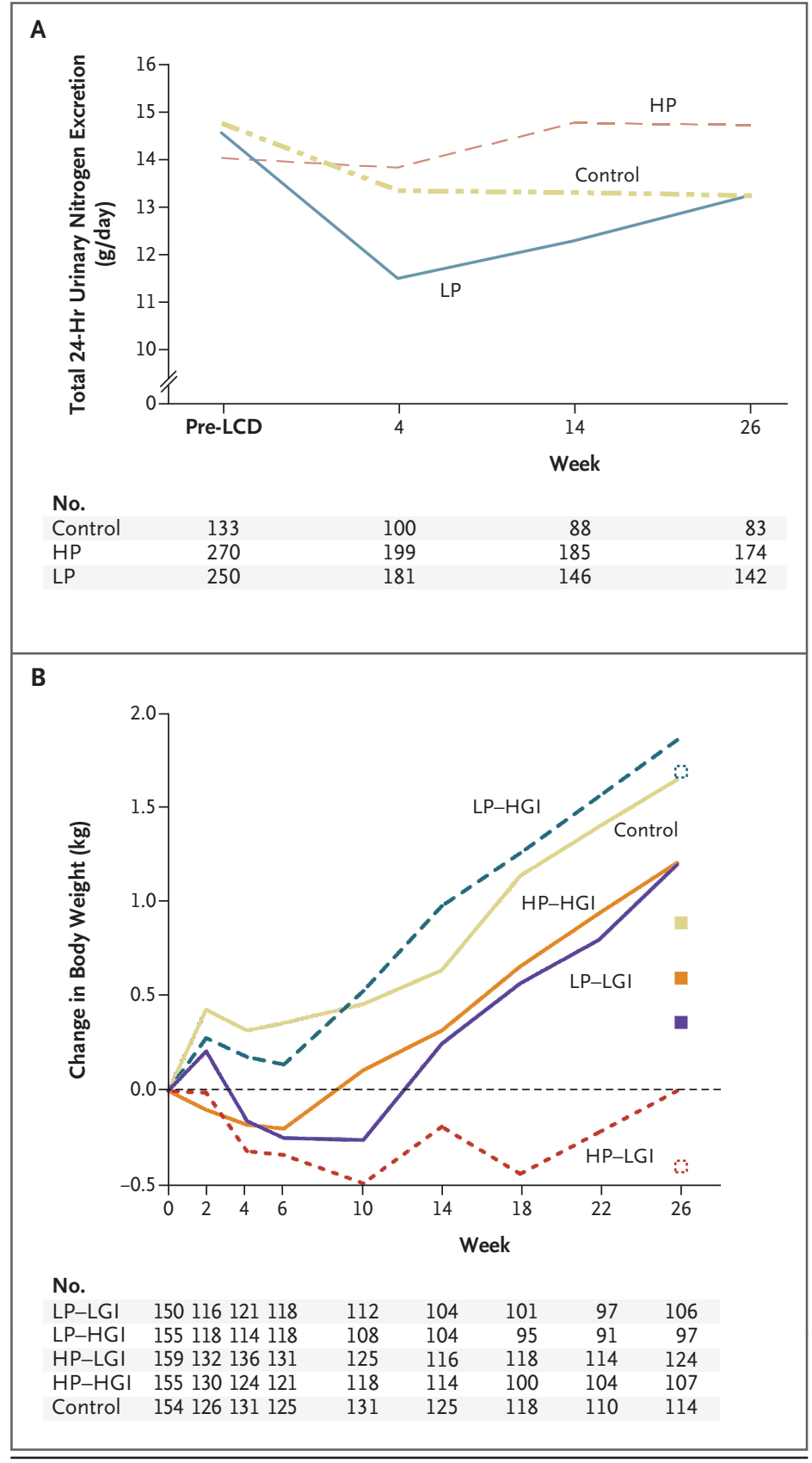

of adverse events does not suggest any causal relation to the diet (for further details on adverse events, see the Supplementary Appendix).

\section{DISCUSSION}

In this study, the rate of completion of the intervention and the rate of maintenance of weight loss were higher among participants who were assigned to the high-protein diets and to the low-glycemic- 


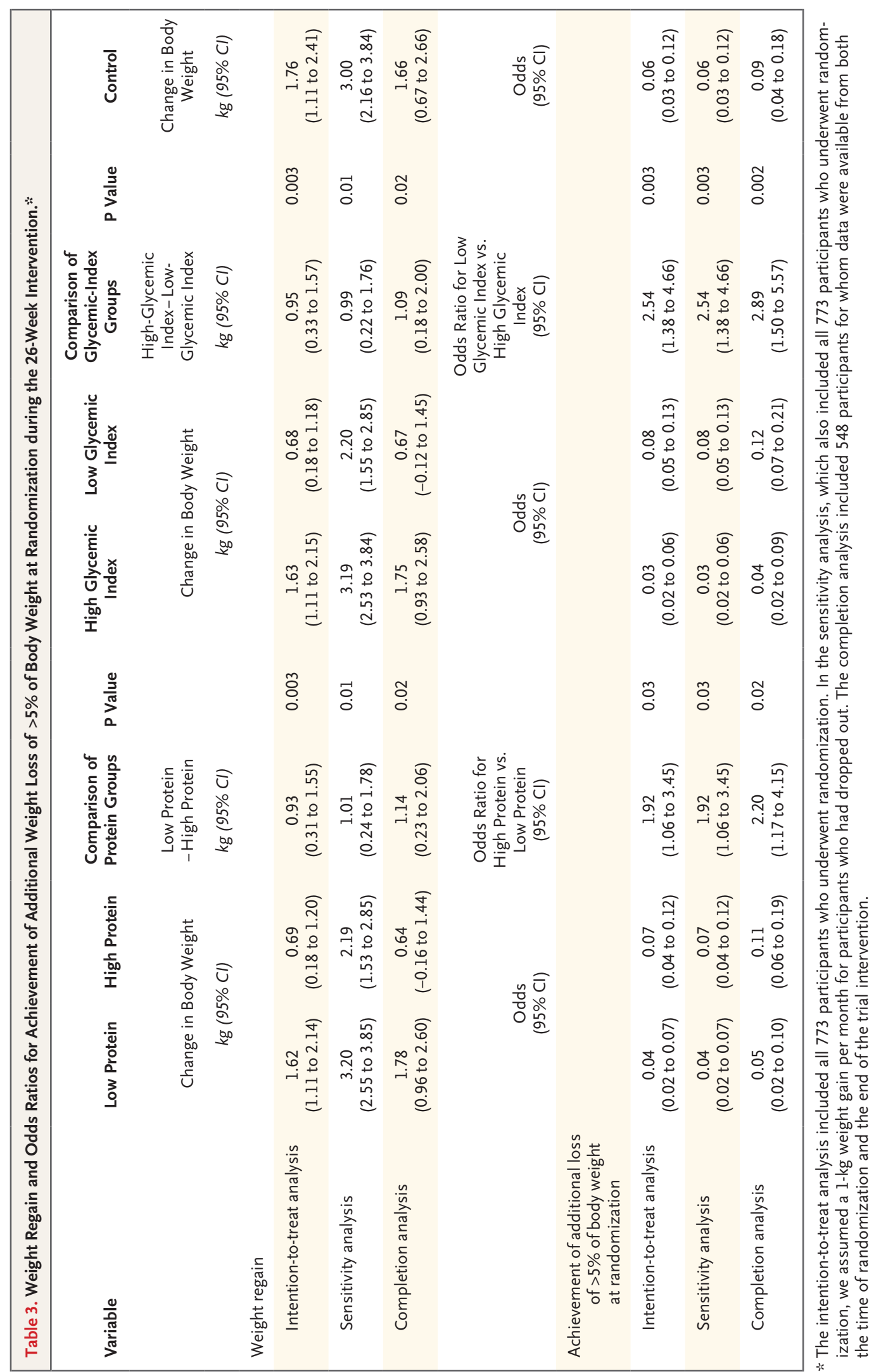


index diets than among those who were assigned to the low-protein diets and to the high-glycemicindex diets (with no restrictions on energy intake in any of the diets). In addition, the participants assigned to the diet that was high in protein with a low glycemic index continued to lose weight after the initial weight loss. The higher protein content was achieved by reducing the carbohydrate content, which adds further support to the concept that reducing the glycemic load (defined as carbohydrate content times glycemic index) is important for controlling body weight in obese patients. ${ }^{8,18,19}$ No differences were detected in self-perceived satiety, though we suspect that the effects were too subtle to be subjectively perceived or measured with the use of visual-analogue scales.

The dietary intervention was carefully controlled to avoid differences in total fat, alcohol, and fiber among the groups but did not fully achieve the targeted difference of approximately $12 \%$ of total energy consumed in protein between the high-protein and the low-protein groups or the targeted difference of approximately 15 glycemicindex units between the low-glycemic-index and the high-glycemic-index groups. The differences that were achieved in the study were 5.4 percentage points of total energy in protein content between the high-protein and the low-protein groups and 4.7 glycemic-index units between the low-glycemic-index and the high-glycemic-index groups.

Measurement of urinary nitrogen excretion confirmed adherence to the diets (high-protein vs. low-protein), but adherence decreased toward the end of the study. Suboptimal adherence, perhaps owing to insufficient knowledge of the content of local foods, may have accounted for the failure to reach the targeted differences in protein and glycemic index. However, the results indicate that even a modest increase in dietary protein or a modest reduction in glycemic-index values was sufficient to minimize weight regain and promote further weight loss in obese patients after a successful weight-loss diet. Higher dietary adherence might have resulted in even greater weight loss.

We used families as the unit of randomization, since we thought that adult participants would be more likely to adhere to the diet if the entire family had the same diet. The participants who underwent randomization in our study were probably a more adherent group than participants in other studies, since they had adhered sufficiently to the low-calorie diet (3.3 MJ [800 $\mathrm{kcal}$ ] per day) for 8 weeks to lose at least $8 \%$ of their body weight. Despite issues of adherence, we believe that our results are generalizable to obese people, particularly if diets are facilitated by easy access to low-glycemic-index foods and a culture that supports these dietary changes.

The dropout rate $(29 \%)$ was higher than the expected rate of $20 \%,{ }^{11}$ possibly owing to difficulty in maintaining motivation in whole families over the course of the 26 weeks of the study. Other dietary studies have reported similar dropout rates. .,18 $^{1,18}$

We conducted a smaller study with the shop model and ad libitum food, and we found that after a 6-month intervention, a high-protein diet resulted in weight loss that was $3.7 \mathrm{~kg}$ greater than that achieved with a low-protein diet. ${ }^{19}$ The current study aimed to investigate whether participants who have had a major weight loss could maintain the lower weight; the results of the study are similar to those of McMillan-Price et al., who found that participants following highprotein diets lost about $0.6 \mathrm{~kg}$ more than did participants following low-protein diets over the course of 3 months. ${ }^{20}$

A reduction in the glycemic index of 4.7 units resulted in a $0.95-\mathrm{kg}$ difference in body weight between the high-glycemic-index groups and the low-glycemic-index groups. Since there were no differences in fiber intake, the difference in body weight, though small, can be ascribed to a true effect of the glycemic index. This difference is consistent with results from a previous study. ${ }^{21}$ Furthermore, a Cochrane meta-analysis of intervention studies showed that there was a $1.1-\mathrm{kg}$ greater weight loss with low-glycemic-index diets than with high-glycemic-index diets. ${ }^{9}$ However, previous studies were designed to investigate weight loss, not weight maintenance, rendering direct comparisons difficult. McMillan-Price et al. did not observe a significant difference in weight loss between diets that differed by 20 glycemicindex units. ${ }^{20}$ Sloth et al. found a $0.6-\mathrm{kg}$ (nonsignificant) difference between diets that differed by 24 glycemic-index units. ${ }^{22}$ Philippou et al. found no significant differences in weight change between maintenance diets that differed by 14 glycemic-index units (approximately $1.0 \mathrm{~kg}$ ). ${ }^{23}$

The effects of protein and the glycemic index 
on changes in body weight that we found in the shop centers were consistent with those at the instruction centers. However, subgroup analyses suggested that the high-protein diets were more effective at the shop centers, whereas the lowglycemic-index effect was greater at the instruction centers. The control diet was designed according to guidelines in each participating country and provided a slightly higher proportion of calories from protein than that in the low-protein groups (19\% vs. $17 \%$ of total energy consumed), with a glycemic index between the high-glycemic-index and low-glycemic-index diets. Thus, the change in body weight that was observed in the control group was as expected, given the protein content and glycemic-index value of the diet. Weight regain in our study was relatively low $(0.56 \mathrm{~kg})$, and the overall weight loss in all participants who completed the intervention was therefore quite high $(10.6 \mathrm{~kg})$, as compared with the total weight loss in most studies of similar length.

In conclusion, in this large, randomized study, a diet that was moderately high in protein content and slightly reduced in glycemic index improved the rate of completion of the intervention and maintenance of weight loss and therefore appears to be ideal for the prevention of weight regain.

The Diogenes project was supported by a contract (FP6-2005513946) from the European Commission Food Quality and Safety Priority of the Sixth Framework Program. Local sponsors made financial contributions to the shop centers, which also received a number of foods free of charge from food manufacturers. A full list of these sponsors can be seen at www.diogenes-eu.org/ sponsors/.

Drs. Meinert Larsen and Astrup report that their department, the Department of Nutrition at the University of Copenhagen, has received research support from more than 100 food companies for this and other studies. Dr. Astrup reports serving as an executive board member of Obesity International Trading (United Kingdom), Beer Knowledge Institute (the Netherlands), Global Dairy Platform (United States), and Nordic Food Lab (Denmark); serving on the European Almond Advisory Board and on the boards of 7TM Pharma, NeuroSearch, Basic Research, Merck, Johnson \& Johnson Pharmaceutical Research and
Development, Jenny Craig, and Kraft; acting as a consultant or advisory board member for 7TM Pharma, NeuroSearch, Basic Research, Merck, Johnson \& Johnson Pharmaceutical Research and Development, Pfizer, Vivus, Jenny Craig, Almond Board of California, and Kraft; and receiving lecture fees from the $\mathrm{Al}$ mond Board of California, Arla, Campina, and Astellas Pharma. Dr. van Baak reports receiving lecture fees from Nutrition et Santé (Belgium), and Asociación General Fabricantes de Azúcar (Spain); she also reports that her institution, Maastricht University Medical Center, received research support from Top Institute Food and Nutrition (Wageningen, the Netherlands) and a commercial obesity treatment center, Center for Obesity Europe (Heerlen, the Netherlands). Dr. Pfeiffer reports serving as a board member or receiving consulting fees from Danone Medical Nutrition and also reports that his institution, the German Institute of Human Nutrition, receives grants from Bundesministerium für Bildung und Forschung, the German Diabetes Foundation, Bayer, and Rettenmayer and Söhne. Dr. Jebb reports serving as a board member of Coca-Cola, PepsiCo, Heinz, Kellogg's, Nestle, and the Almond Board of California (the fees for all board memberships are given to her institution, the Elsie Widdowson Laboratory), receiving consulting fees from Tanita UK, and receiving payment from Rosemary Conley Enterprises for the development of educational presentations, a magazine column, and interviews on nutrition and weight management; she also reports that her institution receives grant support from the World Cancer Research Fund, Tanita, WeightWatchers, CocaCola, and Sanofi-Aventis. Dr. Kunešová reports that her institution, the Institute of Endocrinology Obesity Management Center, has received support or research grants from Unilever, Institute Danone, Milcom-Dairy Research Institute of the Federation of the Food and Drink Industries of the Czech Republic, Novo Nordisk, Abbott Laboratories, Merck, Sanofi-Aventis, Pfizer, and Schering-Plough (now Merck). Dr. Stender reports receiving consulting fees from Novartis and Kowa Research Institute and lecture fees from Merck, Pfizer, and Roche; he also reports that his department at the Gentofte University Hospital has received payment for participation in drug trials sponsored by Pfizer, Merck, Kowa Research Institute, Novartis, Johnson \& Johnson, Cyncron, Parexel, Sanofi-Aventis, AstraZeneca, Bayer, and Janssen-Cilag. Dr. Saris reports receiving consulting fees from Nutrition and Santé (Belgium), serving on the boards of Food for Health (Ireland), International Life Sciences Institute Research Foundation (Washington, DC), McDonalds (Oak Brook, IL), and the Institute for Cardiovascular and Metabolic Research (Reading, UK), being a member of review panels for INRA (France), Genome (Canada), and NordForsk (Norway), and being a parttime employee of Corporate Scientist Nutrition at DSM (the Netherlands); he also reports that his institution, the Maastricht University Medical Center, receives research support from the Dutch Dairy Foundation and Novo Nordisk. No other potential conflict of interest relevant to this article was reported.

Disclosure forms provided by the authors are available with the full text of this article at NEJM.org.
REFERENCES

1. Astrup A, Grunwald GK, Melanson EL, Saris WH, Hill JO. The role of low-fat diets in body weight control: a meta-analysis of ad libitum dietary intervention studies. Int J Obes Relat Metab Disord 2000;24:1545-52.

2. Gardner CD, Kiazand A, Alhassan S, et al. Comparison of the Atkins, Zone, Ornish, and LEARN diets for change in weight and related risk factors among overweight premenopausal women: the A
TO Z Weight Loss Study: a randomized trial. JAMA 2007;297:969-77. [Erratum, JAMA 2007;298:178.]

3. Hession M, Rolland C, Kulkarni U, Wise A, Broom J. Systematic review of randomized controlled trials of low-carbohydrate vs. low-fat/low-calorie diets in the management of obesity and its comorbidities. Obes Rev 2009;10:36-50.

4. Astrup A, Meinert LT, Harper A. Atkins and other low-carbohydrate diets: hoax or an effective tool for weight loss? Lancet 2004;364:897-9.

5. Eisenstein J, Roberts SB, Dallal G, Saltzman E. High-protein weight-loss diets: are they safe and do they work? A review of the experimental and epidemiologic data. Nutr Rev 2002;60:189-200.

6. Halton TL, Hu FB. The effects of high protein diets on thermogenesis, satiety and weight loss: a critical review. J Am Coll Nutr 2004;23:373-85. 
7. Paddon-Jones D, Westman E, Mattes RD, Wolfe RR, Astrup A, WesterterpPlantenga M. Protein, weight management, and satiety. Am J Clin Nutr 2008; 87:1558S-1561S.

8. Brand-Miller JC, Holt SH, Pawlak DB, McMillan J. Glycemic index and obesity. Am J Clin Nutr 2002;76:281S-285S.

9. Thomas DE, Elliott EJ, Baur L. Low glycaemic index or low glycaemic load diets for overweight and obesity. Cochrane Database Syst Rev 2007;3:CD005105.

10. Livesey G, Taylor R, Hulshof T, Howlett J. Glycemic response and health - a systematic review and meta-analysis: relations between dietary glycemic properties and health outcomes. Am J Clin Nutr 2008;87:258S-268S.

11. Larsen TM, Dalskov S, van Baak M, et al. The Diet, Obesity and Genes (Diogenes) Dietary Study in eight European countries - a comprehensive design for long-term intervention. Obes Rev 2010;11: 76-91.

12. Epidata, version $3-$ a comprehensive tool for validated entry and documentation of data. Odense, Denmark: Epidata Association, 2004.

13. Moore CS, Lindroos AK, Kreutzer M, et al. Dietary strategy to manipulate ad libitum macronutrient intake, and glycae- mic index, across eight European countries in the Diogenes Study. Obes Rev 2010;11: 67-75.

14. Rasmussen LG, Larsen TM, Mortensen PK, Due A, Astrup A. Effect on 24-h energy expenditure of a moderate-fat diet high in monounsaturated fatty acids compared with that of a low-fat, carbohydrate-rich diet: a 6-mo controlled dietary intervention trial. Am J Clin Nutr 2007; 85:1014-22.

15. Skov AR, Toubro S, Raben A, Astrup A. A method to achieve control of dietary macronutrient composition in ad libitum diets consumed by free-living subjects. Eur J Clin Nutr 1997;51:667-72.

16. Aston LM, Jackson D, Monsheimer S, et al. Developing a methodology for assigning glycaemic index values to foods consumed across Europe. Obes Rev 2010; 11:92-100.

17. Gadbury GL, Coffey CS, Allison DB. Modern statistical methods for handling missing repeated measurements in obesity trial data: beyond LOCF. Obes Rev 2003;4:175-84

18. Miller M, Beach V, Sorkin JD, et al. Comparative effects of three popular diets on lipids, endothelial function, and C-reactive protein during weight maintenance. J Am Diet Assoc 2009;109:713-7.
19. Skov AR, Toubro S, Ronn B, Holm L, Astrup A. Randomized trial on protein vs carbohydrate in ad libitum fat reduced diet for the treatment of obesity. Int J Obes Relat Metab Disord 1999;23:528-36. 20. McMillan-Price J, Petocz P, Atkinson F, et al. Comparison of 4 diets of varying glycemic load on weight loss and cardiovascular risk reduction in overweight and obese young adults: a randomized controlled trial. Arch Intern Med 2006;166: 1466-75.

21. Ebbeling CB, Leidig MM, Sinclair KB, Hangen JP, Ludwig DS. A reduced-glycemic load diet in the treatment of adolescent obesity. Arch Pediatr Adolesc Med 2003;157:773-9.

22. Sloth B, Krog-Mikkelsen I, Flint A, et al. No difference in body weight decrease between a low-glycemic-index and a highglycemic-index diet but reduced LDL cholesterol after 10-wk ad libitum intake of the low-glycemic-index diet. Am J Clin Nutr 2004;80:337-47.

23. Philippou E, Neary NM, Chaudhri O, et al. The effect of dietary glycemic index on weight maintenance in overweight subjects: a pilot study. Obesity (Silver Spring) 2009;17:396-401.

Copyright (๑) 2010 Massachusetts Medical Society.

POSTING PRESENTATIONS AT MEDICAL MEETINGS ON THE INTERNET Posting an audio recording of an oral presentation at a medical meeting on the Internet, with selected slides from the presentation, will not be considered prior publication. This will allow students and physicians who are unable to attend the meeting to hear the presentation and view the slides. If there are any questions about this policy, authors should feel free to call the Journal's Editorial Offices. 